\title{
Maximizing the Amount of Deposited Particles During a Severe Asthma Attack Using the Stochastic Lung Model
}

\author{
Sarkany Zoltan* \\ University of Medicine and Pharmacy, Tîrgu Mures, Romania
}

\begin{abstract}
Background: The aim of this study was to use a computerized lung model to simulate the deposition of inhaled particles in the human airways during a severe asthma attack, in order to find the combination of breathing- and particle-related parameters which leads to the highest deposited fractions in the target areas of the airways. Material and Method: A stochastic lung model was used to simulate the deposition of $1 \mathrm{~nm}-100 \mu \mathrm{m}$ particles during a severe asthma attack in bronchial generations 9-16. Breathing parameters were chosen to reflect the use of a therapeutic inhalation device, with a 10 s symmetrical breathing cycle and $2000 \mathrm{ml}$ tidal volume. To maximize the deposited fraction in the target areas, further simulations were carried out changing the tidal volume (750-3000 ml), the length of the breathing cycle (2-20 s) and the length of breathing pause following inhalation (0-10 s). Results: The highest deposited fraction of $51.50 \%$ in bronchial generations 9-16 was obtained in the case of $0.01 \mu \mathrm{m}$ particles, this value being more than 4 times higher compared to the highest deposition of 3-6 $\mu \mathrm{m}$ particles currently used in inhalation devices (11.81\% in the case of $5 \mu \mathrm{m}$ particles). Modifying breathing-related parameters did not lead to valuable increases in the deposited fractions in the investigated region. Conclusions: Deposition fractions in the therapeutically important areas of the airways may be more than 4 times higher in the case of $0.01 \mu \mathrm{m}$ particles, compared to particles currently used in the treatment of asthma bronchiale.
\end{abstract}

Keywords: asthma, modelling, stochastic, inhalation, particles

Received: 9 December 2014 / Accepted: 4 June 2015

\section{Introduction}

Asthma is one of the most common chronic diseases of the respiratory system and in the same time the most frequent chronic condition encountered children [1]. The disease is characterized by the inflammation accompanied by episodic obstruction of the airways, causing acute exacerbations, both the chronic form and the acute exacerbations representing a serious health problem

The treatment of asthma bronchiale consists in medication administered mainly by inhalation, using inhaled particles. The diameter used in inhalation devices ranges typically between 3-6 $\mu \mathrm{m}[2,3,4]$, several studies indicating that the ideal size of a particle administrated for treatment of asthma is around $2.8 \mu \mathrm{m}$ [5]. The efficiency of inhalation therapy depends on a large number of breathing-and particle-related factors, and several studies have shown that the efficiency of inhaled therapy is only $10-20 \%[6,7]$, therefore there is a clear need to identify new methods to increase the efficiency of aerosol therapy.

The aim of our study was to simulate the airway deposition of a wide range of inhaled particles during a severe asthma attack, via using a computerized lung model, and to identify the possible factors that could maximize the amount of particles deposited in the target areas, located in the airways.

* Correspondence to: Zoltan Sarkany

E-mail: sarkanyzoltan@gmail.com

\section{Material and methods}

The deposition of inhaled particles during an asthma attack was modelled using the stochastic lung model, taking into account the varying levels of obstruction of the airways and the modified breathing pattern, according to the severity of the attack, as previously presented [8].

We modelled the inhalation of $1 \mathrm{~nm}-100 \mu \mathrm{m}$ particles in an adult male, using parameters characteristic of a severe asthma attack, and calculated the total amount of particles deposited in bronchial generations 9-16. We selected this region as target region due to the fact that $\beta 2$ receptors and smooth muscle cells are present together in this area, which represents the target area for short-acting beta2-agonists. The model used a value for the degree of obstruction selected randomly from an interval of $8-80 \%$ for each bronchial generation, while the functional residual capacity was set to $4500 \mathrm{ml}$ and the probability of obstruction for any given airway to $100 \%$. The simulations were carried out assuming a breathing mode suitable for the use of a therapeutic inhalation device, using a $10 \mathrm{~s}$ symmetrical breathing cycle $($ Tinh $=5 \mathrm{~s}$, Texh $=5 \mathrm{~s})$ with no breathing pause and a $2000 \mathrm{ml}$ tidal volume.

To maximize the deposited fraction of the inhaled particles in the target areas, further simulations were carried out using the particle size that yielded the highest deposition fractions in the first series of simulations, changing one parameter at a time, in a well-defined interval: the tidal volume between $750-3000 \mathrm{ml}$, the length of the breathing cycle between 2-20 seconds and the length of the breath- 
ing pause following inhalation between $0-10 \mathrm{~s}$. Each subsequent simulation was carried out using the parameter value that yielded the highest deposition fraction in the previous simulation. Deposition fractions in the acinar region were also calculated, in order to find the combination of maximum deposition in the target areas and minimum deposition in the acinar region.

It is important to note that although applying a computerized model enables the investigation of an almost endless interval of values, the parameters of this study were investigated in an interval considered to be applicable in case of a patient experiencing a severe asthma attack.

All simulations were carried out for one complete breathing cycle, assuming the inhalation of monodisperse particles through oral breathing and that the particles are inhaled uniformly during inhalation. Data processing and statistical analysis were performed with Microsoft Excel 2010, using Student's t test to compare the results, and a p level below 0.05 was considered to be statistically significant.

\section{Results}

In the first series of simulations we modelledthe deposition of $1 \mathrm{~nm}-100 \mu \mathrm{m}$ particles in bronchial generations 9-16 in case of a severe asthma attack. Deposition fractions of the investigated particles in this area, as well as the acinar region, are presented in Figure 1. Given that deposition values of particles larger than 10 microns were negligible (below 2\%) in the target areas, Figure 1 presents only the deposition values of particles with diameters up to $10 \mu \mathrm{m}$.

Comparing the deposition values of all the investigated particles, we can see that particle diameter has a considerable influence on their deposition. Not taking into consideration $1 \mathrm{~nm}$ particles, which yielded a negligible deposition fraction of $0.29 \%$, the differences between the lowest and the highest deposition fraction can be nearly tenfold (5.19\% in the case of $1 \mu \mathrm{m}$ particles vs. $51.50 \%$ in the case of $0.01 \mu \mathrm{m}$ particles). The highest deposited fraction of $51.50 \%$ in bronchial generations $9-16$ was obtained in the case of $0.01 \mu \mathrm{m}$ particles, while the amount of particles of this size entering the acinar region was $3.58 \%$.

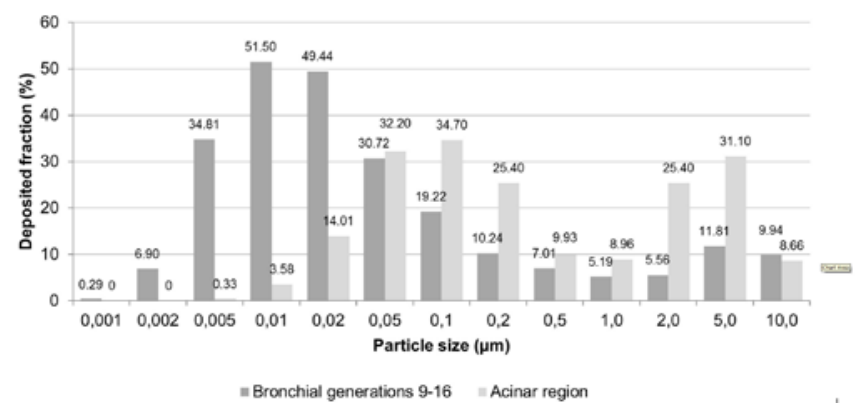

Fig. 1. Total deposition fractions of $1 \mathrm{~nm}-100 \mu \mathrm{m}$ particles in generations 9-16 during a severe asthma attack (FRC $=4500 \mathrm{ml}, \mathrm{V}_{\mathrm{T}}=2000 \mathrm{ml}, \mathrm{T}_{\mathrm{inh}}=5 \mathrm{~s}, \mathrm{~T}_{\mathrm{exh}}=5 \mathrm{~s}$ ). $p<0.001$ for all comparisons.
After establishing that $0.01 \mu \mathrm{m}$ particles yield the highest deposition values in the target areas, the simulations were continued using this particle size, changing the other parameters one at a time. The effect of varying the tidal volume between 750 and $3000 \mathrm{ml}$ is shown in Figure 2.

The results show that tidal volumes smaller than the inital $2000 \mathrm{ml}$ decrease deposition values in the target areas,

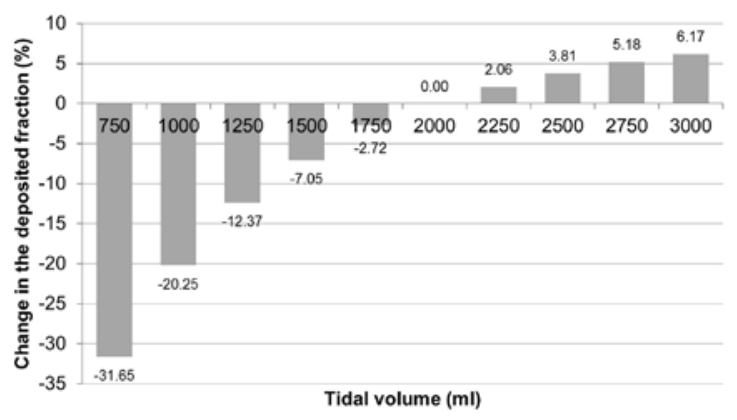

Fig. 2. Percentual change in the deposition fractions of $0.01 \mu \mathrm{m}$ particles in generations 9-16 during a severe asthma attack, with tidal volumes ranging between $750-3000 \mathrm{ml}\left(\mathrm{FRC}=4500 \mathrm{ml}, \mathrm{T}_{\mathrm{inh}}=\right.$ $5 \mathrm{~s}, \mathrm{~T}_{\text {exh }}=5 \mathrm{~s}$ ). $\mathrm{p}<0.001$ for all comparisons.

while larger tidal volumes have an inverse effect. The largest increase, amounting to $6.17 \%(54.68 \%$ vs. $51.5 \%)$ was yielded by a tidal volume of $3000 \mathrm{ml}$, therefore the simulations were continued using this value, varying the length of the breathing cycle between 2 and 20 seconds. The results are presented in Figure 3.

Changing the length of the breathing cycle had an interesting effect, as the $8 \mathrm{~s}$ cycle was the only one that was able to increase the deposition fraction, although only by $0.20 \%$. Continuing with the 8 s symmetrical breathing cycle, the effect of breathing pause following inhalation was investigated, varying its length between 1 and 10 seconds. The results are shown in Figure 4.

Adding a breathing pause after inhalation increased deposition values in bronchial generations 9-16, but only when the pause was between 1-4 seconds. The largest increase of $1.22 \%$ was obtained by applying a $1 \mathrm{~s}$ pause.

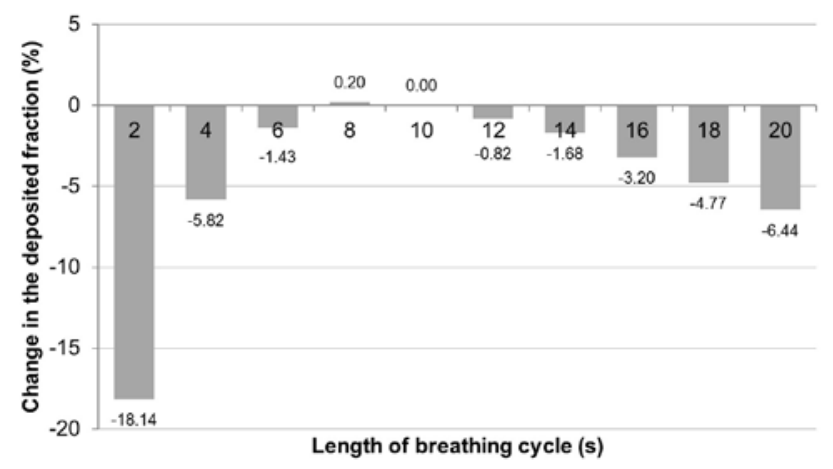

Fig. 3. Percentual change in the deposition fractions of $0.01 \mu \mathrm{m}$ particles in generations 9-16 during a severe asthma attack, with symmetrical breathing cycles ranging between 2-20 s (FRC $=4500$ $\mathrm{ml}, \mathrm{V}_{\mathrm{T}}=3000 \mathrm{ml}$ ). $\mathrm{p}<0.001$ for all comparisons. 


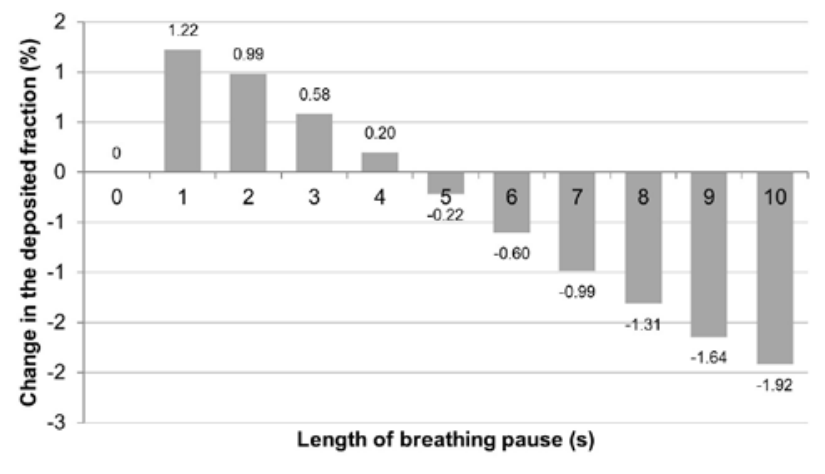

Fig. 4. Percentual change in the deposition fractions of $0.01 \mu \mathrm{m}$ particles in generations 9-16 during a severe asthma attack, with a breathing pause following inhalation ranging between $0-10 \mathrm{~s}$ $\left(F R C=4500 \mathrm{ml}, \mathrm{V}_{\mathrm{T}}=3000 \mathrm{ml}, \mathrm{T}_{\text {inh }}=4 \mathrm{~s}, \mathrm{~T}_{\mathrm{exh}}=4 \mathrm{~s}\right) . \mathrm{p}<0.001$ for all comparisons.

The combined effect of changing thethree key parameters amounted to an increase of $7.41 \%$ of the total deposited fraction in bronchial generations 9-16. The results of the optimization are shown in Figure 5.

\section{Discussion}

In a previous study [8] we have shown that during an asthma attack, the highest deposition fraction obtained in

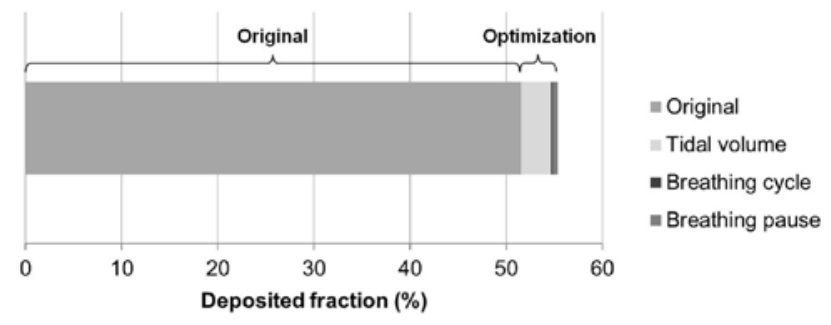

Fig. 5. The combined effect of optimization on the deposition of $0.01 \mu \mathrm{m}$ particles in generations $9-16$ during a severe asthma attack

bronchial generations $9-16$ by particles in the $1-6 \mu \mathrm{m}$ size range is only $11.4 \%$. This percentage can be considered far from efficient, and suggests that there is a need to find methods to optimize the deposition of inhaled therapeutic particles.

Since the deposition of inhaled particles in the human airways is mainly influenced by particle size [9], the most obvious starting point in the optimization undertaken by the present study was to investigate the deposition pattern of particles with a wide range of diameters. Our results suggest that using ultrafine particles of $0.01 \mu \mathrm{m}$ diameter results in deposition fractions more than four times higher compared to particles currently used in the treatment of asthma bronchiale $(51.5 \%$ in the case of $0.01 \mu \mathrm{m}$ particles vs $11.8 \%$ in the case of $5 \mu \mathrm{m}$ particles). At the same time, the fraction of $0.01 \mu \mathrm{m}$ particles entering the acinar region is almost ten times lower compared to $5 \mu \mathrm{m}$ particles (3.58\% for $0.01 \mu \mathrm{m}$ particles vs $31.1 \%$ for $5 \mu \mathrm{m}$ particles), greatly reducing the risk of systemic side effects caused by the absorbtion of the drug into the bloodstream.

Previous simulations carried out with the stochastic lung model have shown that particles in the 1-6 $\mu \mathrm{m}$ size range are influenced to a certain extent to breathing-related parameters [10]. The present study shows that $0.01 \mu \mathrm{m}$ particles are far less sensitive to changes in these parameters, as increases provided by changing the length of the breathing cycle and the length of breathing pause, while statistically significant, can be considered negligible from the patient's point of view. On the other hand, choosing a well-defined tidal volume may provide the patient with approximately $6 \%$ more medication in the target areas. While the investigated parameters and the results of this study are applicable in case of a patient who is experiencing a severe asthma attack, the benefits of using a certain breathing scenario in order to increase particle deposition by a few percents should be evaluated separately for each patient, depending on his/her condition.

Literature data regarding ultrafine particles $(<100 \mathrm{~nm}$ aerodynamic diameter) is limited mostly to their undesirable health effects, especially in relation to the elevated health risks associated with urban air pollution [11-14]. It is generally accepted that children and patients with respiratory diseases are more affected when exposed to ultrafine particles $[15,16]$, and that this exposure leads to a significant increase in the number of asthma exacerbations in the case of these patients [17].Although the underlying mechanism is not fully understood, and may involve the increased diffusion of ultrafine particles due to the inflammation of the airway mucosa [18], these findings suggest that ultrafine particles have an important effect in those regions of the airways which are affected by asthma bronchiale, and could have significant benefits when used in therapeutic devices to treat this condition.Studies from the last few years seem to support this possibility [19], suggesting that the bioactivity of pMDI devices may be attributed to the ultrafine fraction. Recent studies [20] suggest that submicron particles can be a valuable candidate for the improved fluidisation and deposition of aerosol drugs. More studies are needed to assess whether this approach can really lead to an increase in the efficiency of aerosol therapy.

\section{Conclusion}

The results of this study suggest that in comparison with particle currently used for the treatment of asthma bronchiale, a four times higher deposition fraction can be achieved when using $0.01 \mu \mathrm{m}$ particles in the therapeutically important areas of the airways.

\section{Acknowledgement}

This paper is supported by the Sectoral Operational Programme Human Resources Development (SOP HRD), 
financed from the European Social Fund and by the Romanian Government under the contract number POSDRU/159/1.5/S/133377.

\section{References}

1. ${ }^{* * \star}$ Global Inititiative for Asthma. Global strategy for asthma management and prevention 2014. Available fromhttp://www.ginasthma.org

2. Mitchell JP, Nagel MW, Wiersema KJ, Doyle CC. Aerodynamic particle size analysis of aerosols from pressurized metered-dose inhalers: Comparison of andersen 8-stage cascade impactor, next generation pharmaceutical impactor, and model 3321 aerodynamic particle sizer aerosol spectrometer. AAPS PharmSciTech, 2003;4:425-433.

3. Usmani OS, Biddiscombe MF, Barnes PJ. Regional lung deposition and bronchodilator response as a function of beta2-agonist particle size. Am J Respir Crit Care Med, 2005;172:1497-1504.

4. Saini D, Biris AS, Srirama PK, Mazumder MK. Particle size and charge distribution analysis of pharmaceutical aerosols generated by inhalers. Pharm Dev Technol, 2007:12:35-41.

5. Zanen P, Go LT, Lammers JW. Optimal particle size for beta 2 agonist and anticholinergic aerosols in patients with severe airflow obstruction. Thorax, 1996 Oct;51:977-80.

6. Usmani OS, Biddiscombe MF, Nightingale JA, Underwood SR, Barnes PJ. Effects of bronchodilator particle size in asthmatic patients using monodisperse aerosols. J Appl Physiol, 2003;95:2106-2112.

7. Zaninudin BMZ, Biddiscombe M, Tolfree SEJ, Short M, Spiro SG.Comparison of bronchodilator responses and deposition patterns of salbutamol inhaled from a pressurized metered dose inhaler, as a dry powder inhaler and as a nebulised solution. Thorax, 1990;45:469-473.

8. Sárkány Z, Horvath A, Balashazy I, Hofmann W, Brinzaniuc K, Sabau M. Evaluation of inhaled drug deposition during an asthma attack using a stochastic lung model. Acta Medica Transilvanica, 2013;2:238-240.

9. Dolovich M. Influence of inspiratory flow rate, particle size, and airway calibre on aerosolised drug delivery to the lung. Respir Care, 2000:45:597-608
10. Sárkány Z. Morfometria căilor respiratorii inferioare, utilitate în studii de modelare. PhD thesis, University of Medicine and Pharmacy of Târgu Mureș, Romania, 2013, pp. 75-80

11. Oberdorster G. Pulmonary effects of inhaled ultrafine particles. International Archives ofOccupational and EnvironmentalHealth, 2001;74:1-8.

12. Oberdorster G, Gelein RM, Ferin J, Weiss B. Associationof particulate air pollution and acute mortality: involvementof ultrafine particles? Inhalation Toxicology, 1995; 7:111-124.

13. Oberdorster G, Maynard A, Donaldson K, et al. Principlesfor characterizing the potential human health effects fromexposure to nanomaterials: elements of a screening strategy.Particle and Fibre Toxicology, 2005; 2, article 8.

14. Pedata P, Garzillo EM,Sannolo N. Ultrafine particlesand effects on the organism: literature review. Giornaleltaliano di Medicina del Lavoro ed Ergonomia, 2010;32:23-31.

15. Park SK, O'Neill MS, Vokonas PS, Sparrow D, Schwartz J. Effects of air pollution on heart rate variability: theVA normative aging study. Environmental Health Perspectives, 2005;113:304-309.

16. Frampton MW, Utell MJ, Zareba W, et al.Effects ofexposure to ultrafine carbon particles in healthy subjects andsubjects with asthma. Research Report, 2004;126:1-47.

17. Evans KA, Halterman JS, Hopke PK, Fagnano M, Rich DQ. Increased ultrafine particles and carbon monoxide concentrations are associated with asthma exacerbation among urban children. Environ Res, 2014;129:11-19.

18. Olvera HA, Perez D, Clague JW, et al. The Effect of Ventilation, Age and AsthmaticCondition on Ultrafine Particle Deposition in Children. Pulmonary Medicine, vol. 2012, Article ID 736290, 9 pages, 2012. doi:10.1155/2012/736290

19. Crampton M1, Kinnersley R, Ayres J.Sub-micrometer particle production by pressurized metered dose inhalers. J Aerosol Med, 2004 Spring:17:33-42.

20. Faiyazuddin $M$, Mujahid $M$, Hussain $T$, et al. Aerodynamics and deposition effects of inhaled submicron drug aerosol in airway diseases. Recent Pat Inflamm Allergy Drug Discov, 2013;7:49-61. 